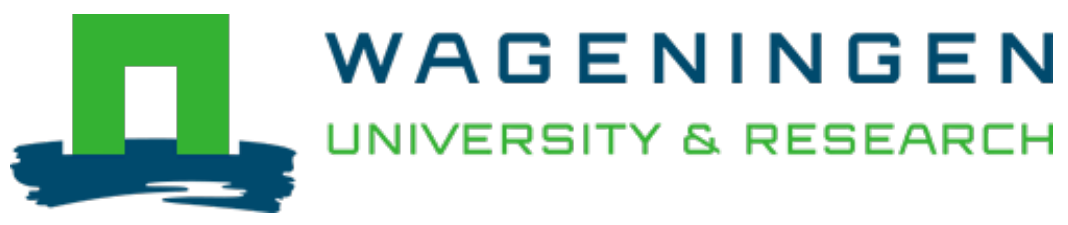

\title{
Effect of Rhizopus and Neurospora spp. on growth of Aspergillus flavus and A. parasiticus and accumulation of aflatoxin B1 in groundnut.
}

\author{
Mycological Research \\ Nout, M.J.R. \\ https://doi.org/10.1016/s0953-7562(89)80046-2
}

This publication is made publicly available in the institutional repository of Wageningen University and Research, under the terms of article $25 \mathrm{fa}$ of the Dutch Copyright Act, also known as the Amendment Taverne. This has been done with explicit consent by the author.

Article 25 fa states that the author of a short scientific work funded either wholly or partially by Dutch public funds is entitled to make that work publicly available for no consideration following a reasonable period of time after the work was first published, provided that clear reference is made to the source of the first publication of the work.

This publication is distributed under The Association of Universities in the Netherlands (VSNU) 'Article $25 \mathrm{fa}$ implementation' project. In this project research outputs of researchers employed by Dutch Universities that comply with the legal requirements of Article $25 \mathrm{fa}$ of the Dutch Copyright Act are distributed online and free of cost or other barriers in institutional repositories. Research outputs are distributed six months after their first online publication in the original published version and with proper attribution to the source of the original publication.

You are permitted to download and use the publication for personal purposes. All rights remain with the author(s) and / or copyright owner(s) of this work. Any use of the publication or parts of it other than authorised under article $25 \mathrm{fa}$ of the Dutch Copyright act is prohibited. Wageningen University \& Research and the author(s) of this publication shall not be held responsible or liable for any damages resulting from your (re)use of this publication.

For questions regarding the public availability of this publication please contact openscience.library@wur.nl 


\title{
Effect of Rhizopus and Neurospora spp. on growth of Aspergillus flavus and $A$. parasiticus and accumulation of aflatoxin $B_{1}$ in groundnut
}

\author{
M. J. R. NOUT \\ Department of Food Science, Agricultural University, Bomenweg 2, 6703 HD Wageningen, The Netherlands
}

Effect of Rhizopus and Neurospora spp. on growth of Aspergillus flavus and A. parasiticus and accumulation of aflatoxin $\mathrm{B}_{1}$ in groundnut. Mycological Research 93 (4): 518-523 (1989).

The influence of Rhizopus and Neurospora spp. on growth and aflatoxin $\mathrm{B}_{1}$ accumulation of Aspergillus flavus and A. parasiticus was investigated. When inoculated simultaneously with Rhizopus or Neurospora spp. on mashed groundnuts, Aspergillus spp. were able to grow, but to a lesser extent and with visually different mycelial development and sporulation behaviour. Accumulation of aflatoxin $\mathrm{B}_{1}$ observed during a $6 \mathrm{wk}$ incubation, averaged $34 \%$ in mixed cultures with Rhizopus spp. and $1 \cdot 7 \%$ in mixtures with Neurospora spp., as compared to pure cultures of Aspergillus spp. On aqueous groundnut extract, selected strains of Rhizopus and Neurospora showed the ability to cause an exhaustion particularly of $C$ compounds, inhibiting Aspergillus growth and aflatoxin $B_{1}$ accumulation. There was also evidence for the formation of Rhizopus and Neurospora metabolites inhibiting growth and/or aflatoxin $\mathrm{B}_{1}$ production. In addition Rhizopus and Neurospora strains degraded aflatoxin $\mathrm{B}_{1}$.

Key words: Aspergillus, Rhizopus, Neurospora, Mixed culture, Aflatoxins.

Under natural conditions, the growth of Aspergillus flavus Link: Fr. var. flavus and $A$. parasiticus Speare as well as the accumulation of aflatoxins are influenced by a number of factors. These include the genetic make-up of these species determining their capability to produce and degrade aflatoxins (Hesseitine, 1979); physical environment, i.e. temperature (Wieman et al., 1986; Magan \& Lacey, 1984; Bullerman, 1985), water activity (Wieman et al., 1986; Magan \& Lacey, 1984), pH (Bullerman, 1985), aeration (Hesseltine, 1979); chemical composition of the substrate, i.e. presence of growth inhibitors (Zaika \& Buchanan, 1987) or precursors of aflatoxin biosynthesis (Buchanan \& Stahl, 1984); and the influence of other micro-organisms. With regard to the latter, the influence of microflora interactions in grain storage situations has been reported (Magan \& Lacey, 1985; Horn \& Wicklow, 1983; Ehrlich et al., 1985). Another situation where microflora interaction plays a role is in the fermentation of foods. In this respect, Ko (1974) reported that Rhizopus microsporus var. oligosporus (Saito) Schipper \& Stalpers NRRL 5905 and Neurospora sitophila Shear \& B. O. Dodge ATCC 14151 opposed to the accumulation of aflatoxins by Aspergillus flavus CBS 120.62 during the fermentative production of tempe and oncom, respectively. He referred to this as 'self-protection of fermented foods'.

The aim of this paper is to broaden the data reported by Ko and to investigate the nature of the self-protection. Hypothetically, several processes may prevent or reduce the accumulation of aflatoxins in fermented foods. These could be classified as follows: (a) competition for nutrients or aflatoxin precursors; (b) formation of substances inhibitory to the biosynthesis of aflatoxins; and (c) biodegradation of aflatoxins which were formed previously. This paper attempts to evaluate the role of such effects.

\section{MATERIALS AND METHODS}

\section{Cultures and biological materials}

The following cultures were obtained from collections: Aspergillus flawus 006 (NRRL $5906=\mathrm{CBS}$ 120.62), $A$. parasiticus 013 (NRRL 2999) and 014 (ATCC $15517=$ CBS 260.67), Rhizopus oligosporus 571 (NRRL 5865) and 575 (NRRL 5905), R. microsporus van Tiegh. var. microsporus 574 (CBS 699.68), Neurospora crassa Shear \& B. O. Dodge 421 (ATCC 24914) and 425 (ATCC 14151). Pure cultures isolated from Indonesian tempe included: $R$. oryzae Went \& Prinsen Geerligs 581, $R$. oligosporus 592, 593, 594, T-8, T-9 and T-10. The strains $R$. microsporus var. chinensis (Saito) Schipper \& Stalpers 589 and $R$. oligosporus 591 were isolated from Indonesian tempe inoculum, whereas $R$. microsporus $573, R$. oryzae 583 and 588 were isolated from Dutch tempe. The following cultures were isolated from Indonesian oncom: $R$. oligosporus 0-10 and 0-13, and Neurospora sp. 428, 429, 430, O$3,0-14,0-16,0-17,0-18$ and $0-19$.

Groundnuts were redskins obtained from a Dutch feed mill.

\section{Cultivation and maintenance of fungi}

Aspergilli were grown at $28-30^{\circ} \mathrm{C}$ on slopes of Malt Extract Agar (MEA, Oxoid CM59) and were maintained at $4^{\circ}$ on the 
same medium. Rhizopus and Neurospora cultures were grown at $28-30^{\circ}$ on slopes of Soya Malt Extract Agar (SMEA) obtained as follows: $150 \mathrm{~g}$ dehulled soya-beans were soaked in $250 \mathrm{ml}$ tapwater for $24 \mathrm{~h}$ at room temperature; after discarding the soak water, the beans were boiled $30 \mathrm{~min}$ in fresh tapwater and ground to a mash with an equal weight of fresh tapwater using a Waring blender. After addition of $50 \mathrm{~g}$ MEA the volume was made up to $I l$ and the resulting medium was sterilized for $20 \mathrm{~min}$ at $121^{\circ}$. The cultures were maintained at $4^{\circ}$ on the same medium.

\section{Preparation of spore suspensions}

Cultures were brought to intensive sporulation by incubation for $7 \mathrm{~d}$ at $30^{\circ}$ on slopes of taugé agar (TA) prepared as follows: $100 \mathrm{~g}$ taugé (Mung bean sprouts) were boiled $30 \mathrm{~min}$ in $750 \mathrm{ml}$ tapwater, followed by filtration through filterpaper. After addition of $60 \mathrm{~g}$ sucrose and $20 \mathrm{~g}$ agar, the volume was made up to $1 \mathrm{l}$, the agar was dissolved by boiling and the medium was sterilized for $15 \mathrm{~min}$ at $121^{\circ}$. Fungal spores were harvested by adding $10 \mathrm{ml}$ sterile $0.02 \%$ Tween 80 in distilled water and dislodging by vibration on a whirl-mixer. The suspension was centrifuged $30 \mathrm{~min}$ at $3000 \mathrm{rev} . \mathrm{min}^{-1}$ in sterile centrifuge tubes, washed twice with portions of $10 \mathrm{ml}$ sterile distilled water and suspended in $10 \mathrm{ml}$ sterile distilled water. Viable spores were counted in pour plates of Rose Bengal Chlortetracycline Chloramphenicol agar (RBCC, Difco Cook 0703-01 with addition of filter sterilized solutions containing $100 \mathrm{mg}$ chloramphenicol and $100 \mathrm{mg}$ chlortetracycline per 1 medium) incubated $48 \mathrm{~h}$ at $30^{\circ}$. Spore suspensions were kept at $-20^{\circ}$.

\section{Preparation of groundnut extract}

Groundnut extract (GE) was obtained by shredding $1 \mathrm{~kg}$ raw groundnuts (Moulinex, France) followed by grinding with 2 I tapwater in a Waring blender. After straining, the residue was ground again with I I tapwater and strained. The two filtrates were combined, heated for $15 \mathrm{~min}$ in an autoclave at $121^{\circ}$ and centrifuged $15 \mathrm{~min}$ at $1500 \mathrm{~g}\left(\mathrm{r}_{\mathrm{av}} .30 \mathrm{~cm}\right)$. The supernatant was again heated and centrifuged as before to remove heat-labile components. The supernatant was lyophilized after filtration in a Büchner funnel through paper (Schleicher \& Schüll 520-b). The lyophilized material was dissolved in demineralized water and kept at $-20^{\circ}$ as a concentrated solution ( $50 \% \mathrm{w} / \mathrm{w}$ dry matter content). Before use, the required quantity of concentrate was diluted 50 times to $\mathrm{GE}$ of $1 \% \mathrm{w} / \mathrm{w}$ dry matter content and tyndallized by steaming $30 \mathrm{~min}$ on 3 consecutive days.

\section{Preparation of groundnut extract agar}

Groundnut Extract Agar (GEA) was prepared by dissolving $2 \%$ agar (BBL 11849, Becton Dickinson \& Co., U.S.A.) in GE and sterilizing $15 \mathrm{~min}$ at $121^{\circ}$.

\section{Preparation of shredded groundnut substrate}

Shredded Groundnut Substrate (SGS) was prepared by shredding raw groundnuts (Moulinex, France) followed by grinding 2 parts by weight of shredded groundnut with I part of tapwater in a Waring blender. The resulting mash was sterilized for $30 \mathrm{~min}$ at $121^{\circ}$ in $5 \mathrm{~cm}$ thick layers in crystallizing glass dishes. The resulting hard mass was broken up and distributed in $50 \mathrm{~g}$ portions in sterile Petri dishes under aseptic conditions.

\section{Inoculation and incubation of experimental substrates}

Experiments on GE were carried out with $25 \mathrm{ml}$ portions of liquid covering the bottom of $250 \mathrm{ml}$ glass jars, with loosely fitted 'twist-off' lids. Inoculation was with $0.1 \mathrm{ml}$ of spore suspension containing $10^{5}$ viable spores $\mathrm{ml}^{-1}$ for each strain. Incubation was at $30^{\circ}$ for $7 \mathrm{~d}$.

Experiments on GEA were carried out in glass Petri dishes (II cm diam). After depositing a sterile filter paper disc ( 0.5 $\mathrm{cm}$ diam) on the centre of the agar, an inoculum of $0.25 \mathrm{ml}$ spore suspension of each tested strain containing $10^{5}$ viable spores $\mathrm{ml}^{-1}$ was pipetted onto the disc. Incubation was at $30^{\circ}$ for periods up to $7 \mathrm{~d}$.

Experiments on SGS were carried out in plastic Petri dishes (14 cm diam, Art. 639102, Greiner, The Netherlands). The inoculum consisted of $0.1 \mathrm{ml}$ spore suspension containing $10^{5}$ viable spores $\mathrm{ml}^{-1}$ for each strain tested, on a centrally placed filter paper disc as with GEA. Incubation was at $30^{\circ}$ for $6 \mathrm{wk}$. During this period, Petri dishes were wrapped in polyethylene to prevent excessive moisture losses.

The water activity $\left(a_{w}\right)$ of SGS was 0.98 at inoculation; at the end of the experiments the $a_{w}$ was $0.94-0.97$.

\section{Determination of growth (biomass)}

GEA slabs with fungal mass were removed from their respective Petri dishes and transferred quantitatively into a $600 \mathrm{ml}$ glass beaker containing $100-150 \mathrm{ml}$ distilled water. After covering the beaker with a glass lid, the water was quickly brought to boiling using a microwave oven (Philips 2010G), resulting in a separation of the fungal mass and the medium which dissolved in the water. After cooling to approx. $70^{\circ}$, the suspension was filtered onto a pre-weighed filter paper (Schleicher \& Schüll 520-b) in a Büchner funnel and the residue was washed with $100 \mathrm{ml}$ hot distilled water to remove adhering medium as much as possible. The filter + residue were dried to constant weight in approx. $20 \mathrm{~h}$ at $80^{\circ}$. The biomass determination was corrected for residual medium absorbed in the filter by filtering sterile GEA in the same way. No correction could be made for traces of medium trapped in mycelium.

\section{Visual inspection of mixed cultures}

At regular intervals the exterior of the mixed cultures was observed and compared with pure cultures of the same age on the same substrate. Colony diameter and shape, mycelium height, extent and colour of sporulation were the major criteria for the evaluation of gradual shifts taking place in the balance between the strains growing together. On SGS it took 5-6 wk until a 'stable' exterior was reached. 


\section{Estimation of aflatoxin $B_{1}$ content}

A simplified extraction without clean-up was used as follows: the sample ( $5 \mathrm{ml} \mathrm{GE}$ culture or $10 \mathrm{~g}$ crushed SGS culture) was extracted with respectively 10 or $20 \mathrm{ml}$ chloroform in a weighed $50 \mathrm{ml}$ wide-neck polyethylene vial for $2 \mathrm{~h}$ at room temperature by shaking at $150 \mathrm{rev} \cdot \mathrm{min}^{-1}$ on an orbital shaker (Gallenkamp). Corrections for evaporation were made by weighing. 1-10 $\mu$ l chloroform extracts were directly spotted (Drummond capillary pipettes) on HPTLC plates (Merck, Darmstadt, Art. 5631) which had been activated at 103-105 for $2 \mathrm{~h}$. On each plate, appropriate amounts of quantitative aflatoxin $B_{1}$ standards containing $1 \mu \mathrm{g} \mathrm{ml}^{-1}$ and $10 \mu \mathrm{g} \mathrm{m}^{-1}$, and of a qualitative standard containing aflatoxins $B_{1}, B_{2}, G_{1}$ and $G_{2}$ were run simultaneously. The plates were developed twice in the same direction: first with diethylether, and subsequently with chloroform: acetone $(90: 10 \mathrm{v} / \mathrm{v})$. Quantitation was carried out with a TLC-densitometer (Shimadzu CS-910 with Xenon lamp). Using this method, the detection level was at 10 p.p.b. aflatoxin $B_{1}$.

\section{Competition experiments}

Competition experiments consisted of two stages. During the first stage, growth of a Rhizopus or Neurospora pure culture was established for $7 \mathrm{~d}$ as described under inoculation and incubation of experimental substrates'. For the second stage, the culture liquid was subsequently separated by filtration (Schleicher \& Schüll 520-b), supplemented as specified below, sterilized $15 \mathrm{~min}$ at $121^{\circ}$, and inoculated and incubated with an Aspergillus pure culture as described above. Supplements added during the second stage were: nil (control: exhausted medium); concentrated GE to reconstruct the original concentration of I\% GE dry matter content; $5 \% \mathrm{w} / \mathrm{v}$ mixed carbon source consisting of $2.5 \% \mathrm{w} / \mathrm{v}$ glucose (Art. 8342, Merck, FRG) and $2.5 \% \mathrm{w} / \mathrm{v}$ sucrose (Art. 7651, Merck, FRG); or $0.5 \%$ mixed nitrogen source consisting of $0.34 \% \mathrm{w} / \mathrm{v} \mathrm{L}$ asparagine (No. 37020, BDH Biochemicals, Poole, England) and $0.16 \% \mathrm{w} / \mathrm{v} \mathrm{NH} \mathrm{NO}_{3}$ (Art. 1188, Merck, FRG).

\section{Degradation of aflatoxin $B_{1}$}

Experiments were carried out on aflatoxin $\mathrm{B}_{1}$ produced by Aspergillus pure culture in $\mathrm{GE}$, and on pure aflatoxin $\mathrm{B}_{1}$ added to GE. After supplementation as specified below, and sterilization for $15 \mathrm{~min}$ at $121^{\circ}$, the substrates were inoculated with Rhizopus or Neurospora pure cultures and incubated as described above. Some experimental treatments were supplemented with concentrated GE as described under 'competition experiments'.

\section{RESULTS}

\section{Growth on groundnut extract agar}

Table I represents the growth of pure and simultaneously inoculated mixed cultures of $A$. flavus $006, A$. parasiticus 014 , $R$. oligosporus 575 and $N$. crassa 421 . Mixed cultures with $R$. oligosporus showed a biomass production and exterior similar to pure $R$. oligosporus. However, the mixed culture with $A$. flavus showed more vertical mycelium development after $4 \mathrm{~d}$ of incubation. Mixed cultures with $N$. crassa showed signs of inhibition. The exterior resembled that of the pure $N$. crassa culture but both biomass production and sporulation were retarded. After $5 \mathrm{~d}$ of incubation, the mixed culture with $A$. parasiticus showed Aspergillus mycelium development and sporulation at the edges of the colony.

\section{Growth and aflatoxin $B_{1}$ accumulation in shredded groundnut substrate}

During the $6 \mathrm{wk}$ incubation period, mixed cultures of Aspergillus and Rhizopus strains showed a variation of exterior changes. In most cases, Rhizopus mycelium showed clearly visible growth, and was mixed with, or even overgrown by, fluffy Aspergillus mycelium. Table 2 summarizes exterior features of the mixed cultures; in mixed cultures with Aspergillus, sporulation varied in extent and colour. Neurospora/Aspergillus mixed cultures showed a more constant behaviour. They were all gradually dominated by fluffy Aspergillus mycelium but sporulation remained absent in all tested mixtures. Table 2 also presents the aflatoxin $B_{1}$ accumulated in SGS cultures after $6 \mathrm{wk}$ incubation. In Rhizopus/Aspergillus mixtures, accumulated aflatoxin $\mathrm{B}_{1}$ was $0-179 \%$ of that in pure Aspergillus cultures, with an average of $34 \%$ (S.D. $41 \%$ ). Although most Rhizopus mixed cultures with low aflatoxin $B_{1}$ content also showed reduced or no

Table 1. Growth (as mg dry biomass) and exterior of pure and mixed cultures of Aspergillus flavus, A. parasiticus, Rhizopus oligosporus, and Neurospora crassa, inoculated simultaneously on groundnut extract agar and incubated $6 \mathrm{~d}$ at $30^{\circ}$

\begin{tabular}{llllll} 
Incubation (d) & 2 & 3 & 4 & 5 & 6 \\
\hline A. flavus 006 & $834(\mathrm{~S})^{1}$ & $1265 \mathrm{~S}^{2}$ & $1196 \mathrm{~S}$ & $1206 \mathrm{~S}$ & $958 \mathrm{~S}$ \\
A. parasiticus 014 & $653(\mathrm{~S})$ & $1211 \mathrm{~S}$ & $1235 \mathrm{~S}$ & $1254 \mathrm{~S}$ & $930 \mathrm{~S}$ \\
R. oligosporus 575 & $673(\mathrm{~S})$ & $662 \mathrm{~S}$ & $538 \mathrm{~S}$ & $570 \mathrm{~S}$ & $524 \mathrm{~S}$ \\
N. crassa 421 & $834(\mathrm{~S})$ & $957(\mathrm{~S})$ & $924 \mathrm{~S}$ & $918 \mathrm{~S}$ & $652 \mathrm{~S}$ \\
A. flavus 006 + R. oligosporus 575 & $733 \mathrm{R}^{3}$ & $712 \mathrm{R}$ & $618 \mathrm{RV} \mathrm{V}^{4}$ & $748 \mathrm{RV}$ & $696 \mathrm{RV}$ \\
A. flavus 006 $+N$. crassa 421 & $644 \mathrm{~N}^{5}$ & $657 \mathrm{~N}(\mathrm{~S})^{6}$ & $674 \mathrm{~N}(\mathrm{~S})$ & $701 \mathrm{~N}(\mathrm{~S})$ & $837 \mathrm{~N}(\mathrm{~S})$ \\
A. parasiticus 014 + R. oligosporus 575 & $705 \mathrm{R}$ & $752 \mathrm{R}$ & $702 \mathrm{R}$ & $667 \mathrm{R}$ & $673 \mathrm{R}$ \\
A. parasiticus 014 + N. crassa 421 & $660 \mathrm{~N}$ & $709 \mathrm{~N}(\mathrm{~S})$ & $725 \mathrm{~N}(\mathrm{~S})$ & $894 \mathrm{NAp}$ & $722 \mathrm{NAP}$ \\
\hline
\end{tabular}

${ }^{1}$ (S): start of sporulation; ${ }^{2} \mathrm{~S}$ : fully sporulated; ${ }^{3} \mathrm{R}$ : exterior identical to Rhizopus pure culture; ${ }^{4} \mathrm{RV}$ : similar to Rhizopus pure culture but more vertical mycelium development; ${ }^{5} \mathrm{~N}$ : exterior identical to Neurospora pure culture; ${ }^{6} \mathrm{~N}(\mathrm{~S})$ : similar to Neurospora pure culture but with reduced sporulation; 7 NAp: mainly Neurospora with development of sporulated A. parasiticus at the edges of the mixed colony. 
Table 2. Aflatoxin $\mathrm{B}_{1}$ accumulated by mixed cultures of Aspergillus flavus 006, A. parasiticus 013 and A. parasiticus 014 with Rhizopus or Neurospora strains grown on shredded groundnut substrate for $6 \mathrm{wk}$ at $30^{\circ}$

\begin{tabular}{|c|c|c|c|c|c|c|}
\hline \multirow[b]{2}{*}{ Aspergillus culture } & \multicolumn{2}{|l|}{ A $006^{1}$} & \multicolumn{2}{|l|}{ A 013} & \multicolumn{2}{|l|}{ A 014} \\
\hline & aflatoxin $B_{1}$ & exterior $^{2}$ & aflatoxin $B_{1}$ & exterior & aflatoxin $B_{1}$ & exterior \\
\hline \multicolumn{7}{|c|}{ Mixed culture with: } \\
\hline None (control) & 71 p.p.m. $=100 \%$ & & 117 p.p.m. $=100 \%$ & & 17 p.p.m. $=100 \%$ & \\
\hline $\mathrm{R} 571^{1}$ & $55^{3}$ & FSl & 43 & FSd & 53 & $\mathrm{Sd}$ \\
\hline R 573 & 2 & FSd & 52 & FSSd & 65 & $\mathrm{FSI}$ \\
\hline R 574 & 4 & $\mathrm{Sl}$ & 68 & FSSd & 76 & $\mathrm{Sd}$ \\
\hline R 575 & 131 & FSSd & 163 & FSSd & 33 & $\mathrm{Sl}$ \\
\hline R 581 & $\ll^{4}$ & & $\ll$ & & $\ll$ & \\
\hline R 583 & 113 & FSd & 2 & $\mathrm{~F}$ & 11 & $\mathrm{~F}$ \\
\hline R 588 & 4 & $\mathrm{~F}$ & 71 & $\mathrm{FSl}$ & 4 & $\mathrm{~F}$ \\
\hline R 589 & 179 & & 31 & & 49 & \\
\hline R 591 & 5 & $\mathrm{~F}$ & 11 & $\mathrm{~F}$ & $0 \cdot 4$ & $\mathrm{~F}$ \\
\hline R $592(\mathrm{~T}-4)$ & 8 & $\mathrm{Sd}$ & $\ll$ & FSl & 44 & $\mathrm{Sl}$ \\
\hline R $593(\mathrm{~T}-6)$ & 2 & & 6 & & $0 \cdot 2$ & \\
\hline R 594 (T-7) & 6 & $S d$ & 21 & SSd & 2 & $\mathrm{FSl}$ \\
\hline R T-8 & 90 & $\mathrm{Sd}$ & 28 & SSl & 22 & $\mathrm{Sd}$ \\
\hline R T-9 & 9 & FSSd & 49 & SSd & 19 & $\mathrm{Sd}$ \\
\hline R T-10 & 13 & Sl & 58 & $\mathrm{FSl}$ & 14 & $\mathrm{Sd}$ \\
\hline R $0-10$ & 11 & $\mathrm{Sd}$ & 48 & $\mathrm{FSl}$ & 7 & $\mathrm{FSl}$ \\
\hline R $0-13$ & 34 & FSl & 58 & FSl & 55 & FSd \\
\hline $\mathrm{N} 421^{1}$ & $\mathrm{I}$ & $F$ & 1 & $\mathrm{~F}$ & 6 & $\mathrm{~F}$ \\
\hline N 425 & 2 & $F$ & 20 & $\mathrm{~F}$ & $0 \cdot 2$ & $\mathrm{~F}$ \\
\hline N $428(0-4)$ & $\ll$ & $\mathrm{F}$ & 2 & F & $\ll$ & $\mathrm{F}$ \\
\hline N $429(0-7)$ & $\ll$ & F & $\ll$ & $\mathrm{F}$ & $\ll$ & $\mathrm{F}$ \\
\hline N $430(0-15)$ & $0 \cdot 2$ & $\mathrm{~F}$ & 4 & $\mathrm{~F}$ & $\ll$ & $\mathrm{F}$ \\
\hline N 0-3 & $\ll$ & $\mathrm{F}$ & 2 & $\mathrm{~F}$ & $0 \cdot 3$ & $\mathrm{~F}$ \\
\hline N 0-14 & $0 \cdot 2$ & $\mathrm{~F}$ & 2 & F & 0.5 & $\mathrm{~F}$ \\
\hline N 0-16 & $0 \cdot 2$ & $\mathrm{~F}$ & 3 & $\mathrm{~F}$ & $0 \cdot 7$ & $\mathrm{~F}$ \\
\hline N 0-17 & 1 & $\mathrm{~F}$ & 3 & $\mathrm{~F}$ & 0.6 & $\mathrm{~F}$ \\
\hline N $0-18$ & $0 \cdot 2$ & $\mathrm{~F}$ & 3 & $\mathrm{~F}$ & $0 \cdot 2$ & $\mathrm{~F}$ \\
\hline N 0-19 & 1 & $\mathrm{~F}$ & 9 & $\mathrm{~F}$ & $0 \cdot 3$ & $\mathrm{~F}$ \\
\hline
\end{tabular}

1 A: Aspergillus; R: Rhizopus; N: Neurospora.

${ }^{2}$ F: fluffy (fan-shaped) Aspergillus mycelium present; S: some Aspergillus sporulation in patches; SS: extensive Aspergillus sporulation; 1 : Aspergillus sporulation in light colour shades (yellow, green); $\mathrm{d}$ : Aspergillus sporulation in dark colour shades (brown, black-brown).

${ }^{3}$ Expressed as \% of corresponding control culture.

$4 \ll$ : not detectable.

Aspergillus sporulation, there was no consistent relationship between extent or colour of Aspergillus sporulation and aflatoxin $B_{1}$ content. There were non-sporulated mixed cultures with low ( $R$ 593) as well as high ( $R$ 589) aflatoxin content. Likewise, heavily sporulated mixed cultures could have high ( $R$ 573) as well as low ( $\mathrm{R}$ 594) aflatoxin contents. In contrast, Neurospora/Aspergillus mixed cultures showed a consistent absence of Aspergillus sporulation and a strong reduction of accumulated aflatoxin $B_{1}$ concentrations with an average of $1 \cdot 7 \%$ (s.D. $3 \cdot 6 \%$ ).

\section{Competition and inhibition in groundnut extract}

For the investigation of interactive effects, combinations were chosen which resulted in maximum inhibition of Aspergillus sporulation and aflatoxin $B_{1}$ accumulation in SGS, i.e. Aspergillus 013 with Rhizopus 581 or Neurospora 429. Table 3 shows the biomass of Aspergillus 013 and its aflatoxin $\mathrm{B}_{1}$ accumulation after $7 \mathrm{~d}$ in GE. If the same Aspergillus strain was inoculated on GE on which Rhizopus 581 or Neurospora 429 had previously been grown for $7 \mathrm{~d}$, the biomass production was strongly reduced and no aflatoxin $B_{1}$ could be detected. Reconstitution of GE components limiting the growth in GE exhausted by previous Rhizopus or Neurospora cultivation was carried out by adding concentrated GE to its original concentration. On such reconstituted media, Aspergillus biomass production was still considerably less than in the control, whereas aflatoxin $B_{1}$ could not be detected. The enrichment of exhausted GE with $5 \%$ mixed carbon source resulted in higher Aspergillus biomass production than in the control, but much less than would be calculated on the basis of available carbon. The aflatoxin $B_{1}$ accumulation was even less than in the control. The enrichment of exhausted GE with $0.5 \%$ mixed nitrogen source had no significant effect on biomass or aflatoxin $\mathrm{B}_{1}$ production. 


\section{Degradation of aflatoxin $B_{1}$ in groundnut extract}

Table 4 shows a representation of experiments carried out with aflatoxin $B_{1}$ produced in situ as well as with pure aflatoxin $\mathrm{B}_{1}$ added to GE. Aflatoxin $\mathrm{B}_{1}$ produced by Aspergillus 013 in $G E$ was quite stable during the $3 \mathrm{wk}$ duration of the experiment after the culture filtrate had been sterilized by autoclaving (controls with and without GE reconstitution were included). Although Rhizopus 581 and Neurospora 429 could hardly grow on GE exhausted by Aspergillus 013, both strains showed the ability to reduce the aflatoxin $B_{1}$ content of the medium. This was accompanied by the formation of unidentified fluorescent components with higher $R_{f}$ values compared to aflatoxin $B_{1}$. If $G E$ exhausted by Aspergillus 013 was reconstituted with concentrated GE, Rhizopus 581 biomass

Table 3. Growth (mg biomass dry matter) and aflatoxin $\mathrm{B}_{1}$ accumulation (p.p.m.) by $A$. parasiticus 013 in groundnut extract after previous growth of Rhizopus or Neurospora pure cultures

\begin{tabular}{|c|c|c|}
\hline Aspergillus parasiticus 013 & $\begin{array}{l}\text { Growth } \\
\text { (mg) }\end{array}$ & $\begin{array}{l}\text { aflatoxin } \\
\mathrm{B}_{1} \text { (p.p.m.) }\end{array}$ \\
\hline \multicolumn{3}{|l|}{ Previous culture on GE: } \\
\hline None $\left(\mathrm{A} 013^{1}\right.$ control) & 52 & 1.05 \\
\hline $\mathrm{R} 581^{1} \rightarrow \mathrm{A} 013$ & 16 & $\ll^{5}$ \\
\hline $\mathrm{R} 581 \rightarrow \mathrm{A} \mathrm{013}+\mathrm{GE}^{2}$ & 34 & $\ll$ \\
\hline R $581 \rightarrow \mathrm{A} \mathrm{O} 13+\mathrm{C}^{3}$ & 115 & $0 \cdot 47$ \\
\hline $\mathrm{R} 581 \rightarrow \mathrm{A}_{013}+\mathrm{N}^{4}$ & 5 & $\ll$ \\
\hline $\mathrm{N} 429^{1} \rightarrow \mathrm{A} \mathrm{O} 013$ & $<1$ & $\ll$ \\
\hline $\mathrm{N} 429 \rightarrow \mathrm{A} 013+\mathrm{GE}$ & 29 & $\ll$ \\
\hline $\mathrm{N} 429>\mathrm{A} 013+\mathrm{C}$ & 73 & $0 \cdot 45$ \\
\hline $\mathrm{N} 429 \rightarrow \mathrm{A} 013+\mathrm{N}$ & 7 & $\ll$ \\
\hline
\end{tabular}

1 A: Aspergillus; R: Rhizopus; N: Neurospora; ${ }^{2}+\mathrm{GE}$ : concentrated GE added to give $1 \% \mathrm{w} / \mathrm{v}$ GE dry matter; ${ }^{3}+\mathrm{C}: 5 \% \mathrm{w} / \mathrm{v}$ mixed carbon source added; ${ }^{4}+\mathrm{N}: 0.5 \% \mathrm{w} / \mathrm{v}$ mixed nitrogen source added ${ }^{5} \ll$ : not detectable. production was enhanced compared to its control whereas Neurospora 429 growth was similar to its control. Under these circumstances, the ability of both strains to degrade aflatoxin $B_{1}$ was similar as under conditions of poor growth. In GE to which aflatoxin $B_{1}$ had been added, Rhizopus 581 growth was slightly inhibited, whereas that of Neurospora 429 was not affected. Both strains degraded aflatoxin $B_{1}$ with the formation of multiple unidentified fluorescent compounds with higher $R_{f}$ values than aflatoxin $B_{1}$.

\section{DISCUSSION}

In this investigation, the interaction of mixed cultures was examined under conditions of simultaneous inoculation, since this is the most likely situation during the fermentation of substrates using sub-standard (contaminated) starters. From the results on GEA we concluded that it may take considerable time before an equilibrium between the components of a mixed fungal culture is reached. Consequently, the experiments on SGS were extended to a $6 \mathrm{wk}$ period. On SGS, the behaviour of Rhizopus towards Aspergillus strains and vice versa was variable. Aspergillus sporulation was observed in $47 \%$ of mixed Rhizopus cultures with low, i.e. $<10 \%$ of control, aflatoxin content. Of mixed cultures with higher aflatoxin contents, $82 \%$ showed Aspergillus sporulation. No relationship between extent or colour of sporulation or nature of mycelium development, e.g. smooth, fluffy, homogenous or patchy, and aflatoxin $B_{1}$ accumulation was observed. Remarkably, Aspergillus sporulation was absent in all mixed cultures with Neurospora, and the mycelium development was very much alike. Nevertheless, this was not due to similarity between the Neurospora strains, considering the variation in their growth and sporulation in pure culture. Our data confirm the behaviour of Neurospora 425 (ATCC 14151) on groundnut medium reported earlier by $\mathrm{Ko}_{\mathrm{O}}$ (1974) after a $17 \mathrm{~d}$ incubation period. On the other hand, Ko (1974) reported approx. 50\%

Table 4. Biodegradation of aflatoxin $B_{1}$ in groundnut extract at $30^{\circ}$ by Rhizopus 581 and Neurospora 429

\begin{tabular}{|c|c|c|c|c|c|c|c|}
\hline \multirow[b]{2}{*}{ Incubation period (wk) } & \multirow{2}{*}{$\begin{array}{l}0 \\
\text { AF-B }{ }_{1}^{1} \\
\text { (p.p.m.) }\end{array}$} & \multicolumn{2}{|l|}{1} & \multicolumn{2}{|l|}{2} & \multicolumn{2}{|l|}{3} \\
\hline & & $\begin{array}{l}\text { AF-B } 1 \\
\text { (p.p.m.) }\end{array}$ & $\begin{array}{l}\text { Biomass } \\
\text { (mg) }\end{array}$ & $\begin{array}{l}\text { AF-B } 1 \\
\text { (p.p.m.) }\end{array}$ & $\begin{array}{l}\text { Biomass } \\
\text { (mg) }\end{array}$ & $\begin{array}{l}\text { AF-B } 1 \\
\text { (p.p.m.) }\end{array}$ & $\begin{array}{l}\text { Biomass } \\
\text { (mg) }\end{array}$ \\
\hline A $013^{2}>-($ control $)$ & $0 \cdot 41^{3}$ & 0.39 & 5 & 0.42 & 5 & 0.32 & 4 \\
\hline $\mathrm{A} 013>-+\mathrm{GE}^{5}$ (control) & 0.41 & 0.50 & 21 & $0 \cdot 48$ & 16 & 0.50 & 19 \\
\hline $\mathrm{GE} \rightarrow \mathrm{R} 581^{2}$ & $-^{10}$ & - & 48 & - & 41 & N.D. ${ }^{11}$ & N.D. \\
\hline$A \quad 013 \rightarrow R 581$ & 0.41 & $0 \cdot 20^{6}$ & 10 & $0.22^{7}$ & 7 & $0 \cdot 11^{8}$ & 8 \\
\hline $\mathrm{A} 013 \rightarrow \mathrm{R} 581+\mathrm{GE}$ & 0.41 & $0 \cdot 17^{6}$ & 73 & $0 \cdot 17^{2}$ & 63 & $0 \cdot 16^{8}$ & 65 \\
\hline $\mathrm{GE} \rightarrow \mathrm{N} 429^{2}$ & - & - & 66 & - & 59 & N.D. & N.D. \\
\hline $\mathrm{A} 013 \rightarrow \mathrm{N} 429$ & 0.41 & $0.09^{6}$ & 10 & $0.03^{7}$ & 8 & $0 \cdot 01^{8}$ & 7 \\
\hline $\mathrm{A} 013 \rightarrow \mathrm{N} 429+\mathrm{GE}$ & $0 \cdot 41$ & $0 \cdot 23^{6}$ & 60 & $0 \cdot 04^{7}$ & 47 & $0 \cdot 01^{8}$ & 48 \\
\hline $\mathrm{GE}+\mathrm{AF}-\mathrm{B}_{1}$ (control) & $0.89^{4}$ & 0.89 & 4 & 0.90 & 4 & $0 \cdot 89$ & 4 \\
\hline $\mathrm{GE}+\mathrm{AF}-\mathrm{B}_{1} \rightarrow \mathrm{R} 581$ & 0.89 & 0.55 & 36 & $0 \cdot 24$ & 39 & $0 \cdot 29^{9}$ & 25 \\
\hline $\mathrm{GE}+\mathrm{AF}-\mathrm{B}_{1} \rightarrow \mathrm{N} 429$ & 0.89 & 0.45 & 51 & $0 \cdot 37$ & 53 & $0 \cdot 14^{9}$ & 49 \\
\hline
\end{tabular}

${ }^{1}$ AF- $\mathrm{B}_{1}$ : Aflatoxin $\mathrm{B}_{1} ;{ }^{2} \mathrm{~A}$ : Aspergillus; $\mathrm{R}$ : Rhizopus; N: Neurospora $;{ }^{3}$ Aflatoxin $\mathrm{B}_{1}$ produced in situ by A 013; ${ }^{4}$ pure aflatoxin $\mathrm{B}_{1}$ added to $\mathrm{GE} ;{ }^{5}+\mathrm{GE}$ : addition of concentrated GE to $1 \% \mathrm{w} / \mathrm{v}$ GE dry matter; ${ }^{6}$ single spot of fluorescent metabolite with $R_{\mathrm{f}}>$ aflatoxin $B_{1}{ }^{7}$ single spot of fluorescent metabolite with $R_{\mathrm{r}}>$ spot $^{8} ;{ }^{8}$ single spot of fluorescent metabolite with $R_{\mathrm{f}}>$ spot $^{7} ;{ }^{9}$ multiple fluorescent spots with $R_{\mathrm{f}}$ $>$ aflatoxin $\mathrm{B}_{1} ;{ }^{10}-$ : not detectable; ${ }^{11}$ N.D.: not determined. 
reduced aflatoxin $B_{1}$ content in tempe (fermented soya-beans) inoculated with Rhizopus 575 (NRRL 5905) and Aspergillus 006 (CBS 120.62). Our data indicate that the ability of Rhizopus 575 to oppose aflatoxin $B_{1}$ accumulation on groundnut was observed only with Aspergillus 014. Considering the high water activity of the media used, the availability of water is not likely to be responsible for the observed variation. However, this different behaviour might be explained by the different substrate (soya versus groundnut, respectively) and incubation periods ( $17 \mathrm{~d}$ versus $6 \mathrm{wk}$, respectively) employed. However, we observed that the majority of the Rhizopus mixed cultures caused reduced aflatoxin $B_{1}$ accumulation in groundnut. The variations in exterior and aflatoxin $B_{1}$ content in mixed cultures with Rhizopus underlines the involvement of a complex of factors influencing aflatoxin $B_{1}$ accumulation. Some of these factors were investigated in mixed cultures which showed good mycelium growth by Aspergillus but where aflatoxin $\mathrm{B}_{1}$ and sporulation remained absent.

Simultaneously inoculated mixed cultures tend to resemble 'black boxes': it is hardly possible to interpret their response in terms of environmental or inter-strain influences. In order to simplify the system, the experiments tabulated in Tables 3 and 4 were designed in two consecutive stages with the aim of creating exaggerated situations of nutrient depletion and/or accumulation of inhibitory substances during the first stage. The tables show the response by the strains inoculated during the second stage.

Data presented in Table 3 indicate that competition for carbon rather than nitrogen by Rhizopus 581 and Neurospora 429 plays a role in suppressing the aflatoxin $B_{1}$ accumulation. However, it is clear that biomass production as well as aflatoxin $B_{1}$ synthesis were inhibited by heat-stable compounds produced by Rhizopus 581 and Neurospora 429 as pure cultures in GE. The sterilization of the medium prior to inoculation with Aspergillus 013 rules out the activity of aflatoxin $B_{1}$ degrading enzymes of Rhizopus or Neurospora origin. On the other hand, it has been reported (Bean \& MacFall, 1982) that certain organic acids including fumaric acid inhibit aflatoxin biosynthesis; these may well have been present in the cultures.

The ability to degrade aflatoxin $B_{1}$ by Rhizopus 581 and Neurospora 429 as shown in Table 4 adds to the complex nature of the self-protection of fermented foods as mentioned earlier by Ko (1974). The formation of various fluorescent substances from pure aflatoxin $B_{1}$ by both Rhizopus 581 and Neurospora 429 and the degradation of aflatoxin $B_{1}$ by $R$. oryzae reported earlier (Jarvis, 1971; Cole, Kirksey \& Blankenship, 1972) confirm their ability to metabolize aflatoxin $B_{1}$. However, the nature of the degradation products and their possible toxicity were not investigated.

Apart from the ability of producer strains to degrade aflatoxin $B_{1}$ reported elsewhere (Doyle \& Marth, 1978; Huynh \& Lloyd, 1984), this investigation shows that in mixed fungal communities competition for carbon sources, inhibition of growth and aflatoxin $B_{1}$ biosynthesis, as well as aflatoxin $B_{1}$ degradation by other than producer strains may take place simultaneously, with the overall reduction of aflatoxin $B_{1}$ accumulation.
The technical contributions by Paul in 't Veld, Anita Kokelaar and Vincent Steenhof, Department of Food Science, Agricultural University, Wageningen; and aflatoxin standards and pure aflatoxin $B_{1}$ provided by Ir. H. P. van Egmond, National Institute of Public Health and Environmental Protection, Bilthoven, The Netherlands are gratefully acknowledged.

\section{REFERENCES}

BEAN, G. A. \& MACFALL, J. C. (1982). Microbial interactions as they affect aflatoxin production. In Developments in Industrial Microbiology 23 (38th General Meeting of the Society for Industrial Microbiology, Richmond, Va.), pp. 221-228.

BUCHANAN, R. L. \& STAHL, H. G. (1984). Ability of various carbon sources to induce and support aflatoxin synthesis by Aspergillus parasiticus. Journal of Food Safety 6, 271-279.

BULLERMAN, L. B. (1985). Interactive effects of temperature and $\mathrm{pH}$ on mycotoxin production. Lebensmittel-Wissenschaft und - Technologie 18, 197-200.

COLE, R. J., KIRKSEY, J. W. \& BLANKENSHIP, B. R. (1972). Conversion of aflatoxin $B_{1}$ to isomeric hydroxy compounds by Rhizopus spp. Journal of Agricultural and Food Chemistry 20, 1100-1102.

DOYLE, M. P. \& MARTH, E. H. (1978). Aflatoxin is degraded at different temperatures and $\mathrm{pH}$ values by mycelia of Aspergillus parasiticus. European Joumal of Applied Microbiology and Biotechnology 6, 95-100.

EHRLICH, K., CIEGLER, A., KLICH, M. \& LEE, L. (1985). Fungal competition and mycotoxin production on corn. Experientia 41, 691-693.

HESSELTINE, C. W. (1979). Effect of environmental conditions upon mycotoxin production. In Proceedings of the 5th International Conference on the Global Impacts of Applied Microbiology (GIAM-5, November, 1977), pp. 362-370. Bangkok, Thailand: UNESCO, UNEP, IFS, SEAMEO, ASEAN.

HORN, B. W. \& WICKLOW, D. T. (1983). Factors influencing the inhibition of aflatoxin production in corn by Aspergillus niger. Canadian Joumal of Microbiology 29, 1087-1091.

HUYNH, V. L. \& LLOYD, A. B. (1984). Synthesis and degradation of aflatoxins by Aspergillus parasiticus. I. Synthesis of aflatoxin $B_{1}$ by young mycelium and its subsequent degradation in aging mycelium. Australian Journal of Biological Sciences 37, 37-43.

JARVIS, B. (1971). Factors affecting the production of mycotoxins. Journal of Applied Bacteriology 34, 199-213.

KO, S. D. (1974). Self-protection of fermented foods against aflatoxin. In Proceedings of the IV International Congress of Food Science and Technology III, pp. 244-253. Madrid, Spain: Instituto Nacional de Ciencia y Technologia de Alimentos.

MAGAN, N. \& LACEY, J. (1984). Effect of water activity, temperature and substrate on interactions between field and storage fungi. Transactions of the British Mycological Society 82, 83-93.

MAGAN, N. \& LACEY, J. (1985). Interactions between field, and storage fungi on wheat grain. Transactions of the British Mycological Society 85, 29-37.

WIEMAN, D. M., WHITE, G. M., TARABA, J. L., ROSS, I. J., HICKS, C. L. \& LANGLOIS, B. E. (1986). Production of aflatoxin on damaged corn under controlled environmental conditions. Transactions of the American Society of Agricultural Engineers 29. 1150-1155.

ZAIKA, L. L. \& BUCHANAN, R. L. (1987). Review of compounds affecting the biosynthesis or bioregulation of aflatoxins. Journal of Food Protection 50, 691-708. 